\title{
Validation of Numerical Simulations of Compartment Fires with Forced or Natural Ventilation Using the Fire and Smoke Simulator (FSSIM), CFAST and FDS
}

\author{
JUSTIN WILLIAMSON, CRAIG BEYLER, and JASON FLOYD \\ Hughes Associates, Inc. \\ 3610 Commerce Drive, Suite 817 \\ Baltimore, MD 21227 USA
}

\begin{abstract}
The Fire and Smoke Simulator (FSSIM) Version 1.5 is a continuous time, physics-based simulation of the spread of fire and smoke inside a multi-level, multi-compartment geometry with complex ventilation. The model was developed to aid designers in analyzing the effect of changes in fire protection systems (both passive and active) and compartment layout on fire spread potential. It is also used to provide data on firerelated phenomena (e.g. temperature, smoke, activation of detection system, and effectiveness of active or passive fire protection) to support recoverability and vulnerability analyses. Extensive verification and validation exercises have been performed to demonstrate the applicability of FSSIM for use as a large scale fire hazard analysis tool. Additionally, a novel methodology to account for the known stratification effects of elevated fuel packages has been investigated in FSSIM. The current effort will examine the performance of FSSIM in simulating the 1986 Lawrence Livermore National Laboratory (LLNL) enclosure fire tests. The performance of FSSIM will then be compared to other commonly used fire simulation tools, including the Consolidated Model of Fire and Smoke Transport (CFAST), and the Fire Dynamics Simulator (FDS).

This study is intended to demonstrate the relative level of accuracy that can be obtained from several fire models using simplistic methodologies such as those that may be employed in the design evaluation stage of fire hazard analysis. This effort supports the use of single zone models in the design and fire hazard analysis of highly complex buildings with multiple challenging design fire scenarios.
\end{abstract}

KEYWORDS: compartment fires, design, modeling, validation.

\section{INTRODUCTION}

The 1986 LLNL enclosure fire tests were a series of 64 experiments performed to examine the effects of forced ventilation on fire behavior [1]. These experiments included the variation of forced ventilation rates, natural ventilation, supply air elevation, fire heat release rate, and fire elevation. They also included tests in a single compartment and a compartment with a drop-ceiling plenum. Characteristic material properties of the construction materials used in the experiments are provided in the report and summarized in Table 1. The compartment was instrumented with two fixed, internal rakes of 15 shielded thermocouples and 30 other thermocouples placed throughout the test cell near critical instruments. Other instrumentation included oxygen sensors, carbon dioxide sensors, pressure transducers, and flow meters. The instrumentation provided transient data for the average compartment temperature, layer temperatures, and average plenum temperature. This data is an excellent validation data set to compare against numerical predictions from fire models.

The compartment was $4.0 \mathrm{~m} \times 6.0 \mathrm{~m} \times 4.5 \mathrm{~m}$ and was lined with $\mathrm{Al}_{2} \mathrm{O}_{3}-\mathrm{SiO}_{2}$ ceramic fiberboard. The drop ceiling was made of $19 \mathrm{~mm}$ thick Marinite, at an elevation of $3.0 \mathrm{~m}$ above the floor in the appropriate tests. The drop ceiling had a $0.4 \mathrm{~m} \times 0.4 \mathrm{~m}$ opening connecting to the lower portion of the test cell, and was not constructed to be air tight. The total leakage into the compartment is described as accounting for 20 to $25 \%$ of the exhaust air, and this leakage is estimated as an area of $0.023 \mathrm{~m}^{2}$ applied uniformly to the walls of the enclosure. Some scenarios included natural ventilation in the form of an open doorway with dimensions $2.06 \mathrm{~m} \times 0.76 \mathrm{~m}$, without forced ventilation, although the ductwork was left open to the ambient. Fire intensities in the test series were controlled using a methane burner and ranged from $50 \mathrm{~kW}$ to $400 \mathrm{~kW}$. Forced ventilation was also controlled to provide a constant mass flow rate ranging from $0.0 \mathrm{~kg} / \mathrm{s}$ to $0.5 \mathrm{~kg} / \mathrm{s}$ where applicable. 
Table 1. Material properties provided for the construction materials used in the LLNL enclosure fire tests [1].

\begin{tabular}{|l|c|c|c|}
\hline \multicolumn{1}{|c|}{ Property } & $\begin{array}{c}\text { Walls } \\
\text { (Fiberboard) }\end{array}$ & $\begin{array}{c}\text { Ceiling and } \\
\text { floor } \\
\text { (Fiberboard) }\end{array}$ & $\begin{array}{c}\text { Drop ceiling } \\
\text { (Marinite) }\end{array}$ \\
\hline Thickness, $\mathrm{m}$ & 0.1 & 0.1 & 0.019 \\
\hline Density, $\mathrm{kg} / \mathrm{m}^{3}$ & 1440 & 1920 & 700 \\
\hline Thermal conductivity, $\mathrm{W} / \mathrm{m} \cdot \mathrm{K}$ & 0.39 & 0.63 & 0.12 \\
\hline Specific heat, $\mathrm{J} / \mathrm{kg} \cdot \mathrm{K}$ & 1000 & 1000 & 1120 \\
\hline
\end{tabular}

The LLNL test compartment is illustrated in Fig. 1. The two fixed internal rakes were placed nominally beside the fire as indicated by Fig. 1. The temperature data from the west thermocouple rake was reported as spatial averages of five probes corresponding to the top, middle and bottom of the test cell, as well as an average of all fifteen probes. These averages are calculated as a direct arithmetic mean of thermocouple data, and no obvious effort was made to produce mass weighted averages, time response corrections, or radiation corrected data. This instrumentation was used to determine the average compartment temperature, compartment upper layer temperature, compartment lower layer temperature and average plenum temperature depending on the experimental configuration used.

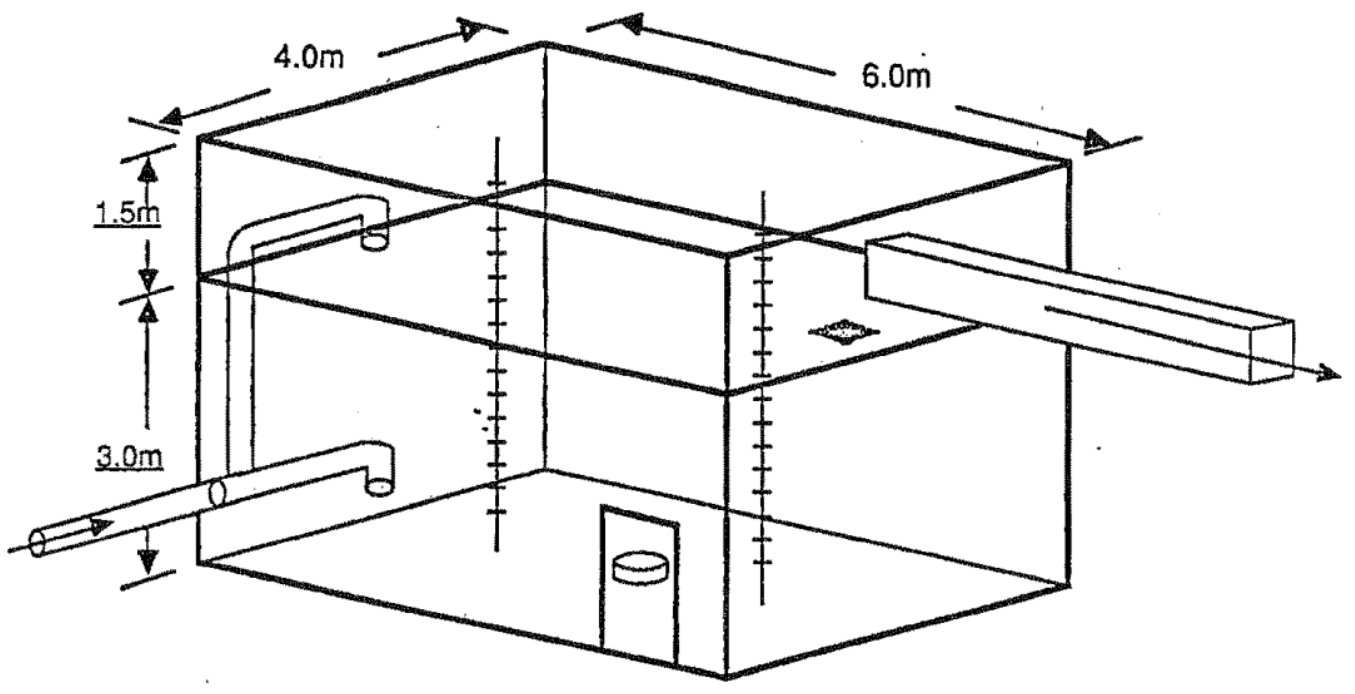

Fig. 1. Schematic of the LLNL fire test cell highlighting important dimensions and object placement [1].

\section{MODEL IMPLEMENTATIONS}

Representative model inputs of the various experimental configurations were created for FSSIM [2,3], CFAST [4], and FDS [5,6]. Each model has its own specific set of requirements and limitations regarding the definition of the geometry and diagnostic outputs. Here, the model inputs are selected in a simple and straightforward manner, similar to what would be done in a design fire hazard analysis, such that each of the three models can be compared to both the experimental data and to each other.

\section{FSSIM Implementation}

The FSSIM [2] simulations were created to represent the data as reported in the test data report, including surface materials and ventilation conditions. Extensive verification and validation exercises have been performed to demonstrate the applicability of FSSIM for use as a large scale fire hazard analysis tool [3]. Fire scenarios that involve substantial transient smoke filling characteristics should not normally be modeled using FSSIM; however, this paper introduces a novel method to account for cases with stable stratification. The full test cell geometry was simulated using a single compartment, unless the fuel source 
was elevated. The plenum test cell geometry was simulated with two compartments, representing both the plenum space and the lower portion of the test cell. In some tests, the fire elevation was increased to heights of $0.3 \mathrm{~m}$ to $1.8 \mathrm{~m}$, and in these scenarios the alternative methodology was used as described below.

FSSIM computes the average temperature for any compartment included in the model, and there is no implicit accounting for stratification in the model. It is expected that, depending upon the exhaust location, temperatures may exceed the compartment average temperature due to stratification of the thermal environment. There are three configuration classes to be examined with respect to stratification:

1. Ventilation supplied high in the space (Fig. 2). The two layer environment converges to a single layer over time due to mixing induced by the supply ventilation. The presence of exhausts both high and low indicates that the configuration may include either or both.

2. Ventilation supplied low in the space and exhausted high in the space with the fire source at or near floor level (Fig. 3). A two layer environment is created, but the steady state layer interface is near the floor.

3. Ventilation supplied low in the space and exhausted high in the space with the fire source well above the floor of the compartment (Fig. 4). A two layer environment is created and the steady state layer interface is just above the fire base.

In these classifications, high and low refer to the vent opening elevations relative to the fire source.

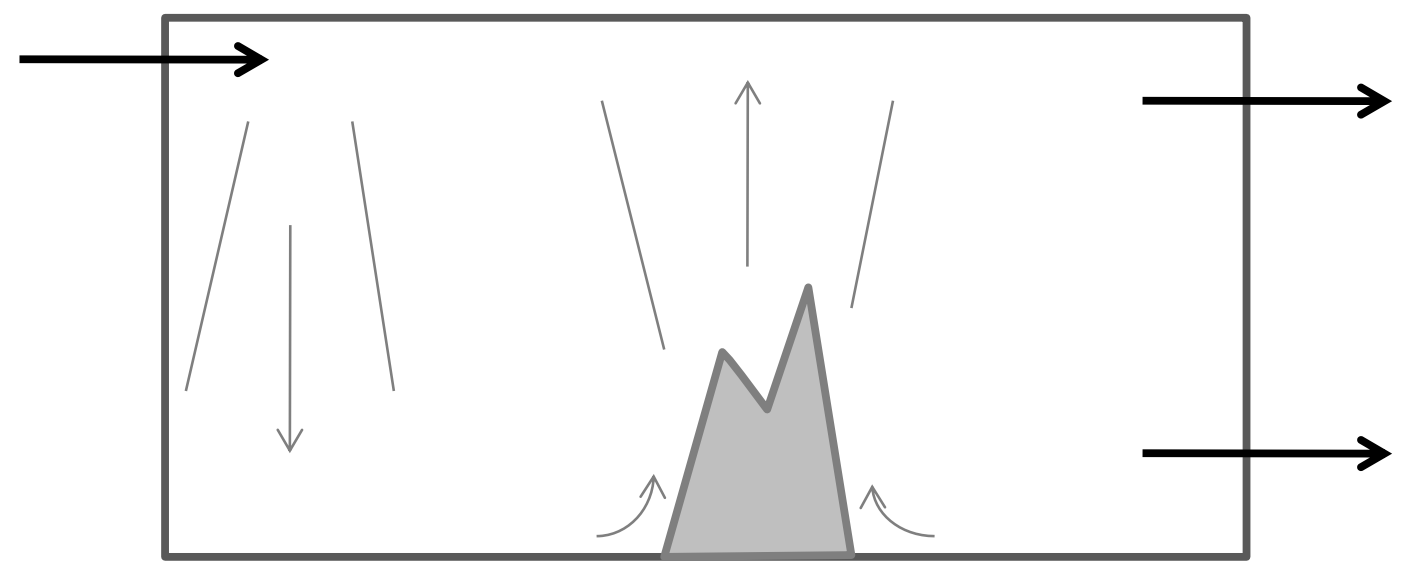

Fig. 2. Compartment fire with supply ventilation provided high in the compartment.

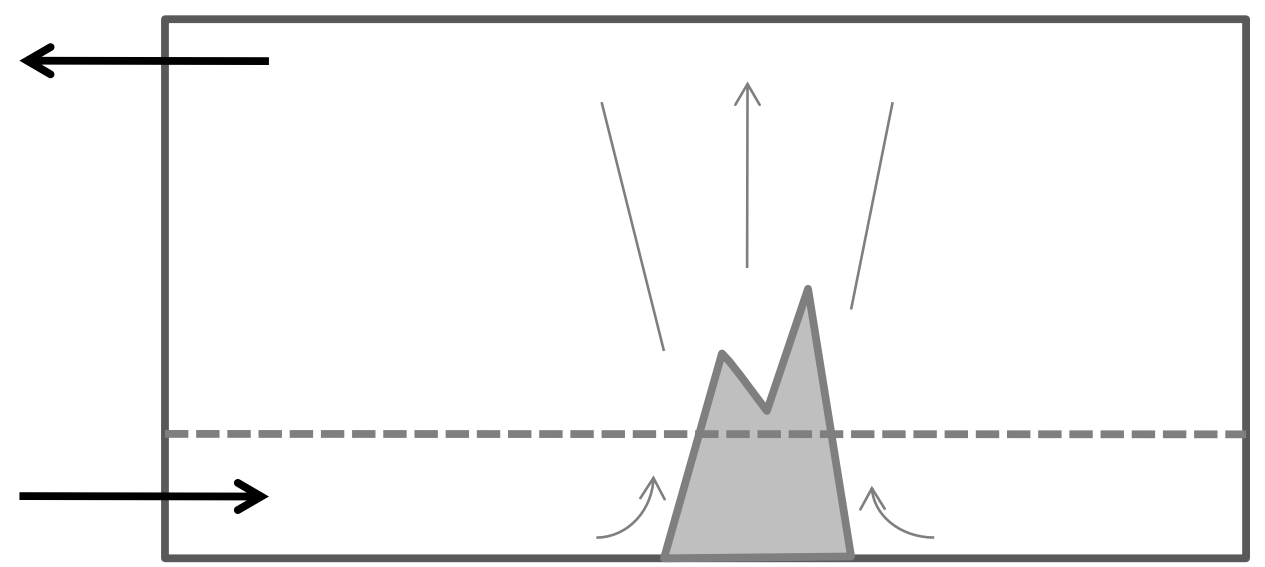

Fig. 3. Compartment fire with supply ventilation provided low in the compartment and the fire near the floor height. 


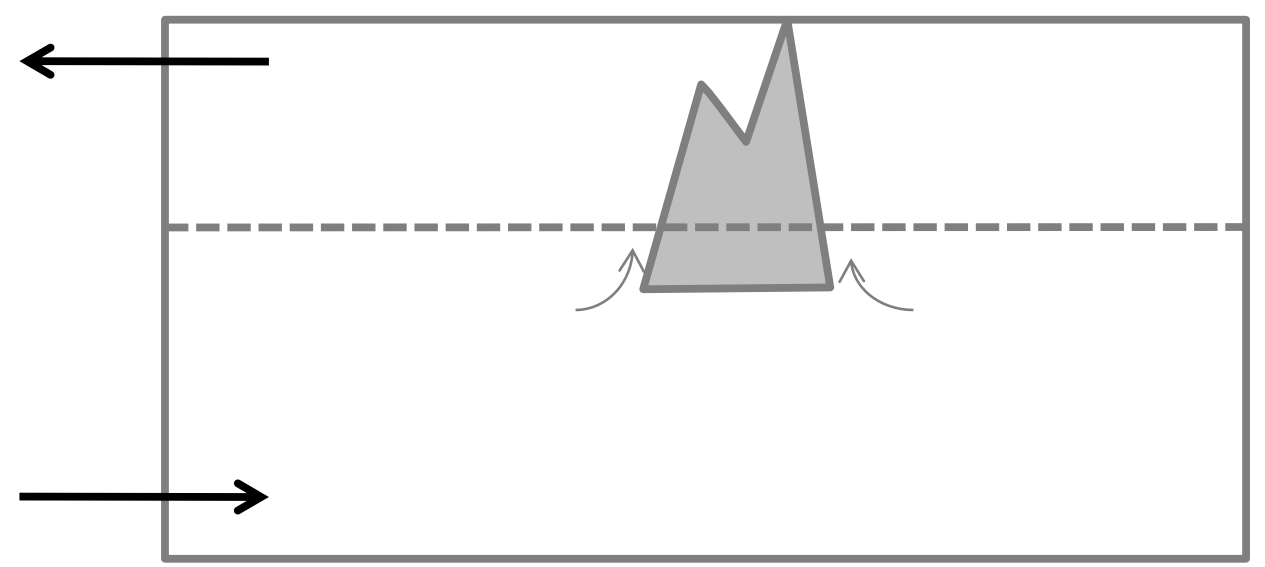

Fig. 4. Compartment fire with supply ventilation provided low in the compartment and the fire well above the floor height.

With supply air being provided high in the space as depicted in Fig. 2, a well mixed environment is typically produced. The forced ventilation provides cool air high in the space with a tendency to move to the floor due to negative buoyancy and momentum if supply is oriented downward at the ceiling. This forms an inverted plume which entrains heated gases as it flows toward the floor, just as the fire plume entrains in the fire plume. These forces yield a substantial recirculation flow that acts to create a uniform, well-mixed environment. Beyler [7] and Peatross and Beyler [8] have identified that the species concentrations are generally more uniform than temperature because species are not lost to compartment boundaries, while thermal energy is lost to these surfaces. Because of the heat loss dynamics, temperature non-uniformities are present. However, if the exhaust is low in the space, the temperatures at the exhaust location are generally below the average compartment temperature. Twenty-four of the tests performed in the 1986 LLNL test series conform to this configuration.

Figure 3 represents the classical ventilation configuration for naturally ventilated compartment fires, with a door type vent leading to stratification. The buoyancy induced circulation causes incoming flow near the floor and exhaust flow in the upper portions of the door. This configuration provided the impetus for two zone fire modeling, such as CFAST [4]. The classical compartment fire fluid dynamics includes a smoke filling period, during which the hot layer descends as the plume flow accumulates below the ceiling. Flow out of the layer begins as soon as the layer descends to the height of the exhaust vent. This first slows the descent of the layer interface and then a fluid dynamical steady state can be achieved in which the layer interface is stationary and the air entrained below the layer by the fire is equal to the exhaust rate from the fire. Because the fire entrainment rate up to the flame height is approximately ten times the stoichiometrically required air (assuming a normal ambient temperature), layer interface heights tend to be in the lower portion of the flame in any situation where significant thermal hazards are involved relative to the volume of the compartment. Thus, for fires on or near the floor of the compartment, the average compartment temperature and the upper layer temperature are approximately equal. Twenty-eight of the tests performed in the 1986 LLNL test series conform to this configuration.

Figure 4 represents a challenging scenario in which the fuel package is located at a significant elevation in the compartment. Exhaust from the ceiling can give rise to hot gases accumulating only above the fire source even when exhaust rates are relatively low. In fact, the characteristics described in the section above for configuration two are applicable here if the room height is taken as the height of the ceiling above the base of the fire. In this case, the hot layer interface will normally stabilize a short distance above the fuel package base. The resulting upper layer temperature and average compartment temperature will be substantially different if the space is modeled as a single compartment. For the purposes of defining thermal hazards, FSSIM may not be appropriately conservative for configuration three conditions. In these scenarios, the lower test cell was divided into two compartments connected by an open vertical vent in FSSIM to account for the predictable effects of stratification in the compartment. The division of the compartment was prescribed at the elevation of the fuel source. This modification of inputs produces an effective two-layer zone model for FSSIM, which improves the capability of the model in simulating a fire with a known stratification. The results of the numerical predictions from FSSIM compared to the 
experimental measurements are illustrated in Fig. 5. Also included in Fig. 5 are the experimental uncertainty bounds represented by solid lines, and the model bias and relative uncertainty represented by the dashed lines, each expressed as $95 \%$ confidence intervals ( $2 \tilde{\sigma}$ ).

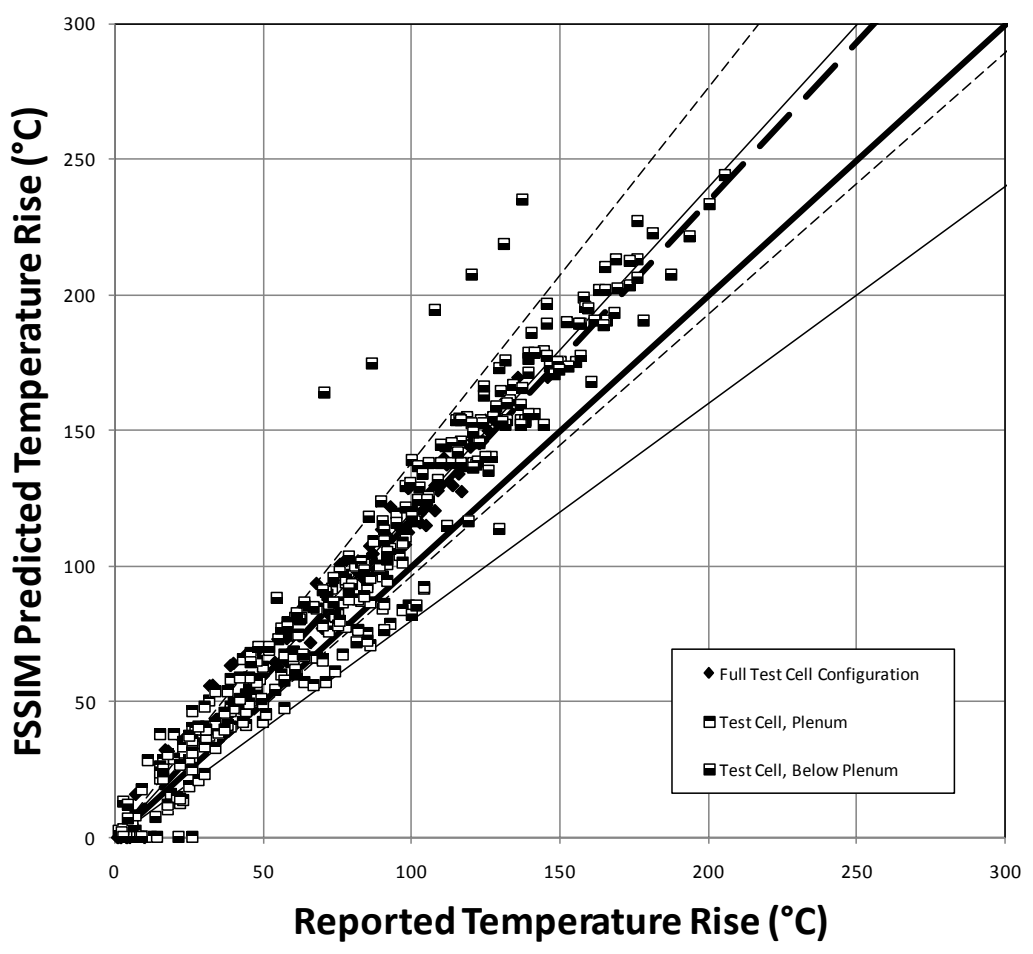

Fig. 5. Comparison of FSSIM predicted compartment temperatures to those reported experimentally [1].

In Fig. 5, the outliers correspond to experimental Test 42, which involves a $1.8 \mathrm{~m}$ elevated fire source $(200 \mathrm{~kW})$ below the plenum with forced ventilation $(0.18 \mathrm{~kg} / \mathrm{s})$. FSSIM is reporting a conservative (high) temperature prediction in the space below the plenum compared to the experimental data. The deviation of Test 42 may be the result of under-prediction of heat transfer to the drop ceiling, partial extinction of the fire, under-prediction of the vertical vent flow between the plenum and the lower test cell, or the location of the thermocouple tree relative to the fire plume. The plenum temperature prediction in this case is within the normal scatter of the data. Overall, FSSIM is producing a conservative prediction of the average compartment temperature, particularly for the tests that achieve higher temperatures and the tests that involve elevated fuel sources.

\section{CFAST Implementation}

CFAST v6.0.10 [4] was used to model the same set of tests. All input parameters for the CFAST input files were set equal (to the extent possible) to the description provided in the LLNL test report [1]. CFAST has the inherent capacity to evaluate elevated fire sources and transient layer effects, and standard methodologies are employed for all fire scenarios.

One notable functional limitation of CFAST is the inability to specify the forced ventilation rate. In the tests, this flow is specified as a constant rate of mass flow, where CFAST is limited to volumetric flow. Given the time varying compartment temperature and pressure, this difference is approximately $20 \%$ on average over the duration of the tests. To account for this variation, the exhaust volumetric flow rate is increased by $20 \%$ from its ambient volumetric flow, which is similar to assuming that the exhaust is $100{ }^{\circ} \mathrm{C}$ on average. This method is preferable to specifying variable volumetric flow ramping, as this would be difficult to implement in CFAST. Likewise, in most applications there is no a priori knowledge of the transient compartment temperature on which to base the rate of change of volumetric flow. The results of the numerical predictions from CFAST compared to the experimental measurements are illustrated in Fig. 6 below. Also included in Fig. 6 are the experimental uncertainty bounds represented by solid lines, and the 
model bias and relative uncertainty represented by the dashed lines, each expressed as $95 \%$ confidence intervals $(2 \tilde{\sigma})$.

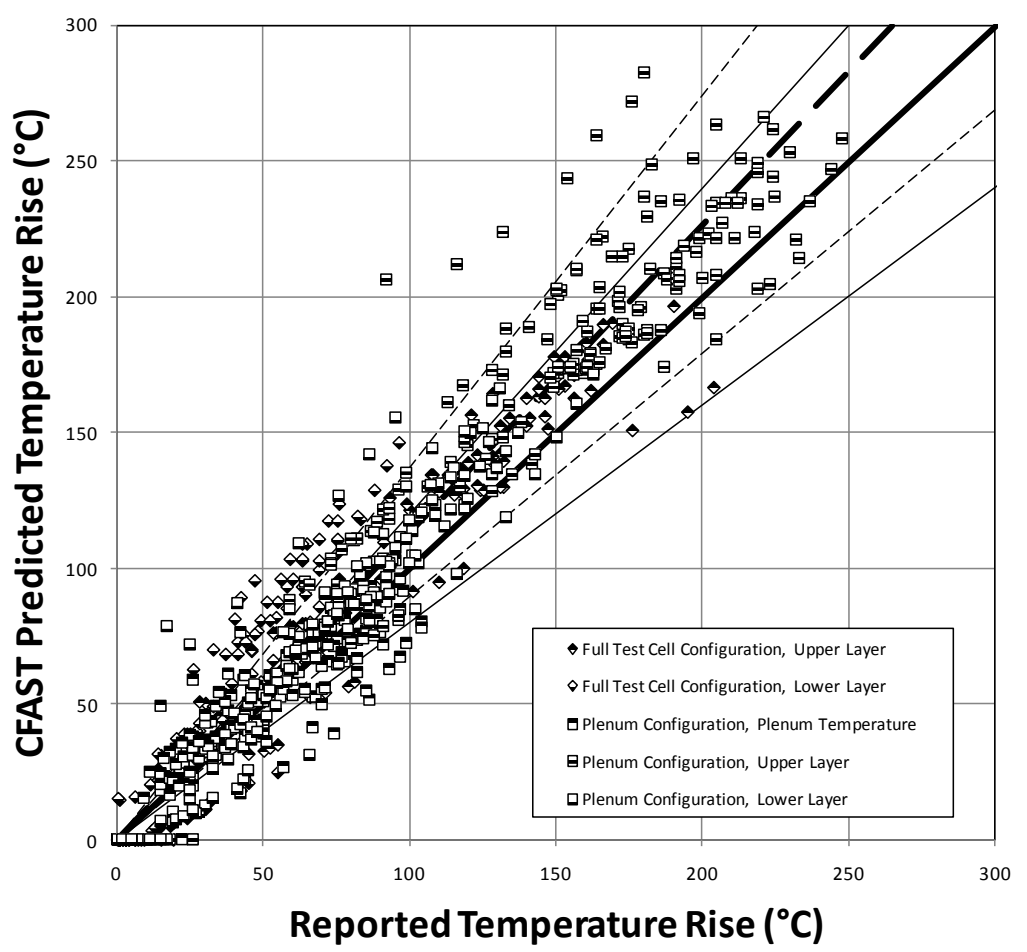

Fig. 6. Comparison of CFAST predicted compartment temperatures to those reported experimentally [1].

In Fig. 6, the volume of the plenum was treated as a uniform average of the five top thermocouples in the test report; therefore, only the average temperature of the plenum compartment is reported from CFAST. The upper and lower layer temperatures are assumed to be equivalent to the five middle thermocouples and the five lower thermocouples respectively. The outliers correspond to Tests 42 and 43 , which involve a 1.8 m elevated fire source $(200 \mathrm{~kW})$ below the plenum with and without forced ventilation (Test $42: 0.18 \mathrm{~kg} / \mathrm{s}$; Test 43: $0.0 \mathrm{~kg} / \mathrm{s}$ with ducts left open). In Tests 42 and 43, CFAST reported a conservative (high) temperature prediction in the space below the plenum compared to the experimental data. The deviation is thought to be the result of under-prediction of heat transfer to the drop ceiling, partial extinction of the fire, under-prediction of the vertical vent flow between the plenum and the lower test cell, or the location of the thermocouple tree relative to the fire plume. The plenum temperature prediction in this case is within the scatter of the data. Overall, CFAST is producing a reasonable prediction of the compartment layer temperatures.

\section{FDS Implementation}

The LLNL test cell was also reproduced for simulation with FDS v5.3.1. All input parameters for the FDS input files were set equal (to the extent possible) to the description provided in the LLNL test report [1]. The computational domain is simulated using $0.1 \mathrm{~m}$ grid spacing for all tests. This corresponds to a characteristic fire diameter to grid spacing ratio of 4 to 7 depending on the specified heat release rate. This resolution is within the recommended range reported by Hill et al. as 4 to 16 for FDS [9]. Given the relatively simplistic burner and compartment configuration in this study, the selected grid is deemed as sufficient to reproduce the average compartment temperatures reported experimentally. It is expected that the accuracy of the FDS simulation can be incrementally improved by a grid resolution study; however, this is not a point of emphasis for this work. This study is intended to demonstrate the relative level of accuracy that can be obtained from several fire models using simplistic methodologies such as those that may be employed in the design evaluation stage of fire hazard analysis. The results of the numerical predictions from FDS compared to the experimental measurements are illustrated in Fig. 7 below. Also included in 
Fig. 7 are the experimental uncertainty bounds represented by solid lines, and the model bias and relative uncertainty represented by the dashed lines, each expressed as $95 \%$ confidence intervals ( $2 \tilde{\sigma}$ ).

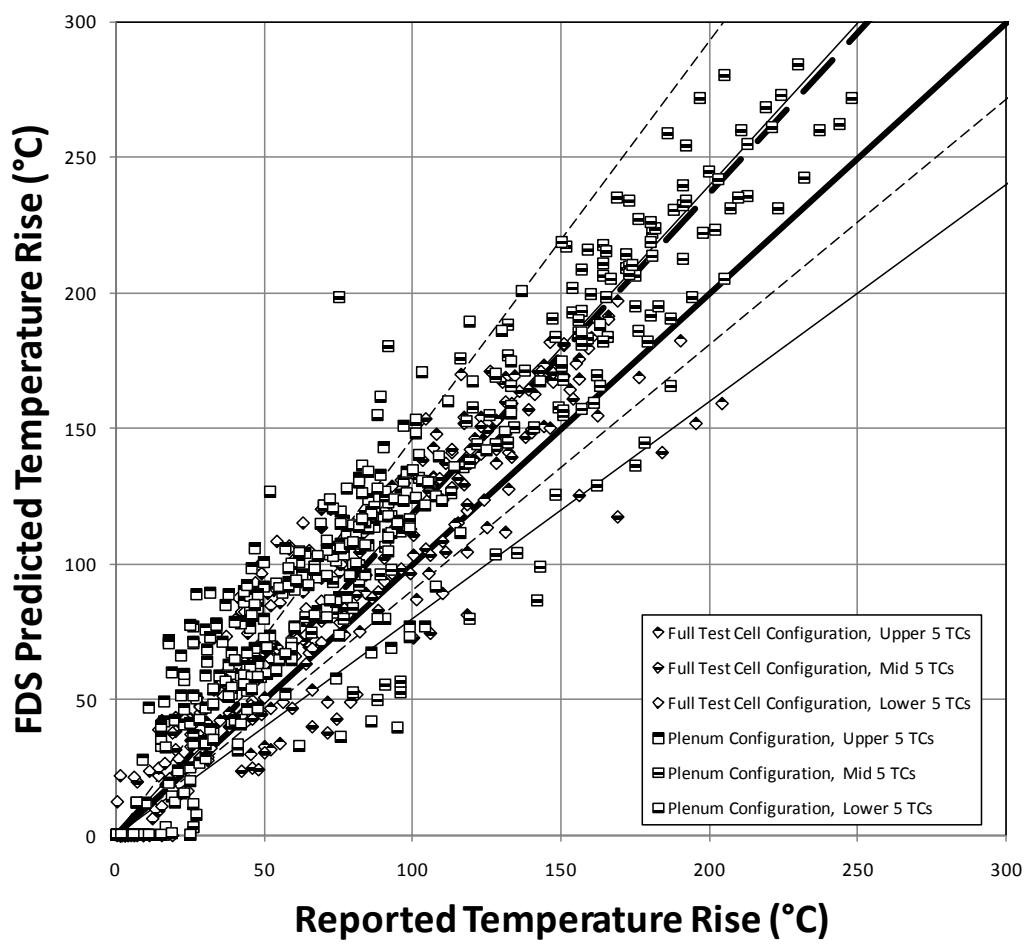

Fig. 7. Comparison of FDS predicted compartment temperatures to those reported experimentally [1].

In Fig. 7, the FDS model prediction is compared to the experimental data reported for averages of five thermocouples with the location of the measurements indicated by the shaded portion of the figure symbol. Tests 42 and 43 are not significant outliers in the FDS analysis, indicating that the physics of these tests are more accurately captured by FDS than in FSSIM or CFAST. In Tests 42 and 43, FDS is also reporting a conservative (high) temperature prediction in the space below the plenum compared to the experimental data, and the predictions are along the top most edge of the scatter in Fig. 7. Overall, FDS is producing a reasonable prediction of the temperatures throughout the test enclosure with no apparent limitations on the configuration of the fuel source or ventilation.

\section{DISCUSSION}

It is clear from the individual model implementations demonstrated above that each of the three models have a similar capacity to reproduce compartment temperatures. This result is expected, as the configuration of the LLNL test series is similar to the configurations that provided the impetus for developing fire models. Nevertheless, it is also clear that each of the models produces some variability in the prediction when compared to the reported experimental results. Simple error analysis has been performed for each model in order to evaluate the conditions of their appropriate use in the context of design fire hazard analysis. The error in temperature is defined as:

$\varepsilon=\frac{T_{M}-T_{E}}{T_{E, \max }-T_{\infty}}$

The subscripts $M$ and $E$ correspond to model and experimental values respectively, and the max corresponds to the maximum reported experimental temperature in the location of interest (i.e. upper layer, lower layer, or plenum). 
Comparisons of the temperature prediction errors associated with Figs. 5, 6 and 7 are illustrated in Tables 2 and 3. On the average, FSSIM, CFAST, and FDS are predicting temperatures between $5 \%$ and $15 \%$ when compared to the reported experimental data. The models also produce a considerable level of variability as indicated by the maximum and minimum observed errors, though this could easily be as a result of the experimental uncertainty. The largest outliers typically occur in locations where the actual temperature rise above ambient is very low, such as in the lower layer and the plenum. These errors are amplified by the definition of the error term, where the denominator of the expression is small. Other outliers are evident in cases where the fuel source is substantially elevated; however, each of the models produces highly conservative results in these configurations. There is essentially no difference in the accuracy of either of these models for this test suite, and each model has a tendency to produce conservative temperature predictions. This indicates that each of these models is appropriate for use in design fire hazard analysis, where the model inputs and specification of the scenario are highly simplified or unknown.

Table 2. Model temperature prediction error for fires in the full test cell configuration.

\begin{tabular}{|l|r|r|r|r|r|r|}
\hline $\begin{array}{c}\text { Temperature } \\
\text { prediction } \\
\text { error }\end{array}$ & $\begin{array}{c}\text { FSSIM } \\
\text { average } \\
\text { comp. }\end{array}$ & $\begin{array}{c}\text { CFAST } \\
\text { upper } \\
\text { layer }\end{array}$ & $\begin{array}{c}\text { CFAST } \\
\text { lower } \\
\text { layer }\end{array}$ & $\begin{array}{c}\text { FDS } \\
\text { upper 5 } \\
\text { TCs }\end{array}$ & $\begin{array}{c}\text { FDS } \\
\text { middle 5 } \\
\text { TCs }\end{array}$ & $\begin{array}{c}\text { FDS } \\
\text { bottom 5 } \\
\text { TCs }\end{array}$ \\
\hline Maximum & $25 \%$ & $18 \%$ & $48 \%$ & $26 \%$ & $27 \%$ & $52 \%$ \\
\hline Minimum & $-5 \%$ & $-18 \%$ & $-29 \%$ & $-22 \%$ & $-28 \%$ & $-3 \%$ \\
\hline Average & $10 \%$ & $5 \%$ & $22 \%$ & $4 \%$ & $6 \%$ & $23 \%$ \\
\hline
\end{tabular}

Table 3. Model temperature prediction error for fires in the test cell with the plenum configuration.

\begin{tabular}{|l|r|r|r|r|r|r|r|r|}
\hline $\begin{array}{c}\text { Temperature } \\
\text { prediction } \\
\text { error }\end{array}$ & $\begin{array}{c}\text { FSSIM } \\
\text { average } \\
\text { comp. }\end{array}$ & $\begin{array}{c}\text { FSSIM } \\
\text { average } \\
\text { plenum }\end{array}$ & $\begin{array}{c}\text { CFAST } \\
\text { upper } \\
\text { layer }\end{array}$ & $\begin{array}{c}\text { CFAST } \\
\text { lower } \\
\text { layer }\end{array}$ & $\begin{array}{c}\text { CFAST } \\
\text { average } \\
\text { plenum }\end{array}$ & $\begin{array}{c}\text { FDS } \\
\text { upper } \\
\text { 5 TCs }\end{array}$ & $\begin{array}{c}\text { FDS } \\
\text { middle } \\
\text { 5 TCs }\end{array}$ & $\begin{array}{c}\text { FDS } \\
\text { bottom } \\
\text { 5 TCs }\end{array}$ \\
\hline Maximum & $47 \%$ & $21 \%$ & $57 \%$ & $35 \%$ & $30 \%$ & $25 \%$ & $49 \%$ & $45 \%$ \\
\hline Minimum & $-9 \%$ & $-13 \%$ & $-8 \%$ & $-21 \%$ & $-31 \%$ & $11 \%$ & $-9 \%$ & $-33 \%$ \\
\hline Average & $13 \%$ & $5 \%$ & $11 \%$ & $6 \%$ & $-1 \%$ & $11 \%$ & $12 \%$ & $14 \%$ \\
\hline
\end{tabular}

Additionally, the size of the dataset explored allows for higher level statistical analysis following the method described for the validation exercises for FDS [6]. The original LLNL test report does not provide an estimate for the experimental uncertainty. However, the test series includes four pairs of experiments with nearly identical input conditions. Comparison of these tests suggests that there is approximately $5 \%$ to $10 \%$ variation across identical tests. The reported experimental data also indicates substantial deviation from the specified constant exhaust rate that ranges by $10 \%$ to $20 \%$ of the set point. Guidance of typical experimental measurements of upper layer gas temperatures suggests that $7 \%$ is a reasonable approximation [6,9]. Given the available experimental data, the relative experimental uncertainty is assumed to be $10 \%\left(\tilde{\sigma}_{E}=0.1\right)$. This allows for the estimation of the model bias $(\delta)$ and relative model uncertainty $\left(\tilde{\sigma}_{M}\right)$ under the following framework [6]:

$$
\begin{aligned}
& E \mid \theta \sim N\left(\theta, \sigma_{E}^{2}\right) ; \quad \tilde{\sigma}_{E}=\sigma_{E} / \theta \\
& M \mid \theta \sim N\left(\delta \theta, \sigma_{M}^{2}\right) ; \quad \tilde{\sigma}_{M}=\sigma_{M} / \delta \theta \\
& \overline{\ln M}=\frac{1}{n} \sum_{i=1}^{n} \ln M_{i} \quad ; \quad \overline{\ln E}=\frac{1}{n} \sum_{i=1}^{n} \ln E_{i}
\end{aligned}
$$


$\tilde{\sigma}_{M}^{2}+\tilde{\sigma}_{E}^{2}=\frac{1}{1-n} \sum_{i=1}^{n}\left[\left(\ln M_{i}-\ln E_{i}\right)-(\overline{\ln M}-\overline{\ln E})\right]^{2}$

$\delta=\exp \left(\overline{\ln M}-\overline{\ln E}+\frac{\tilde{\sigma}_{M}^{2}}{2}-\frac{\tilde{\sigma}_{E}^{2}}{2}\right)$

where $N\left(\mu, \sigma^{2}\right)$ indicates a normal distribution with mean, $\mu$, and standard deviation, $\sigma$, and the quantities $\theta, E$ and $M$ are the true, experimental and modeled quantities of interest. In this case, $E$ and $M$ are defined as the temperature rise above ambient. Quantities that are small in comparison to the standard deviation of experimental measurements are considered not statistically significant, and are filtered out of the statistical analysis. This condition is defined by the standard deviation of the experimentally measured temperatures, where the experimental measurements are treated as a population of random samples. The non-statistically significant quantities are then specified as $M / \sigma_{E}<1.0$. The standard deviation of the experimental measurements was found to be $\sigma_{E}=60{ }^{\circ} \mathrm{C}$ and the result is that all quantities of $M<60^{\circ} \mathrm{C}$ are excluded from the statistical analysis. This methodology ensures that the near ambient temperatures do not define the model uncertainty.

Equations 4, 5 and 6 are evaluated for each model, and the results of this analysis are provided in Table 4, and illustrated as the dashed lines in Figs. 5, 6 and 7 with the model bias $(\delta)$ in bold and the $95 \%$ confidence interval ( $\delta \pm 2 \tilde{\sigma}_{M}$ ) as the fine lines. These results confirm the over prediction of the models when compared to the experimental data and there is essentially no difference in the accuracy of either of these models for this test suite. This supports the conclusion that each of these models is appropriate for use in design fire hazard analysis, where the model inputs and specification of the scenario are highly simplified or unknown. Given that these models may be used in the context of design fire hazard analysis, the uncertainty analysis is useful to define the degree of conservatism, or level of confidence in the analysis.

Table 4. Estimated model bias and relative uncertainty assuming a relative experimental uncertainty of $10 \%\left(\tilde{\sigma}_{E}=0.1\right)$.

\begin{tabular}{|l|l|c|c|}
\hline Model & $\begin{array}{c}\text { Experimental } \\
\text { configuration }\end{array}$ & $\begin{array}{c}\text { Estimated model } \\
\text { bias, } \\
\delta\end{array}$ & $\begin{array}{c}\text { Estimated model } \\
\text { relative } \\
\text { uncertainty, } \tilde{\sigma}_{M}\end{array}$ \\
\hline FSSIM & Full test cell & 1.18 & 0.104 \\
\hline FSSIM & Plenum & 1.17 & 0.105 \\
\hline FSSIM & All data & 1.17 & 0.104 \\
\hline CFAST & Full test cell & 1.18 & 0.122 \\
\hline CFAST & Plenum & 1.12 & 0.118 \\
\hline CFAST & All data & 1.13 & 0.119 \\
\hline FDS & Full test cell & 1.14 & 0.131 \\
\hline FDS & Plenum & 1.22 & 0.148 \\
\hline FDS & All data & 1.19 & 0.140 \\
\hline
\end{tabular}

Some questions still arise in the application of a single zone model such as FSSIM to predict the thermal behavior of a complex fire scenario. Additional scrutiny may be desired in highly sensitive design scenarios that emphasize conservative results. In Figs. 8 and 9, the FSSIM predicted average compartment temperatures are compared against upper layer temperatures predicted by CFAST and FDS respectively. Overall, FSSIM is producing a similar temperature prediction to that of the upper layer in CFAST or FDS, although it is often lower by $10 \%$ to $20 \%$ as would be expected given the fundamental differences in the models. This implies that FSSIM predicted temperature differences above ambient can be adjusted by a factor of $10 \%$ to $20 \%$ in fire hazard analyses where additional conservatism is highly desired. 


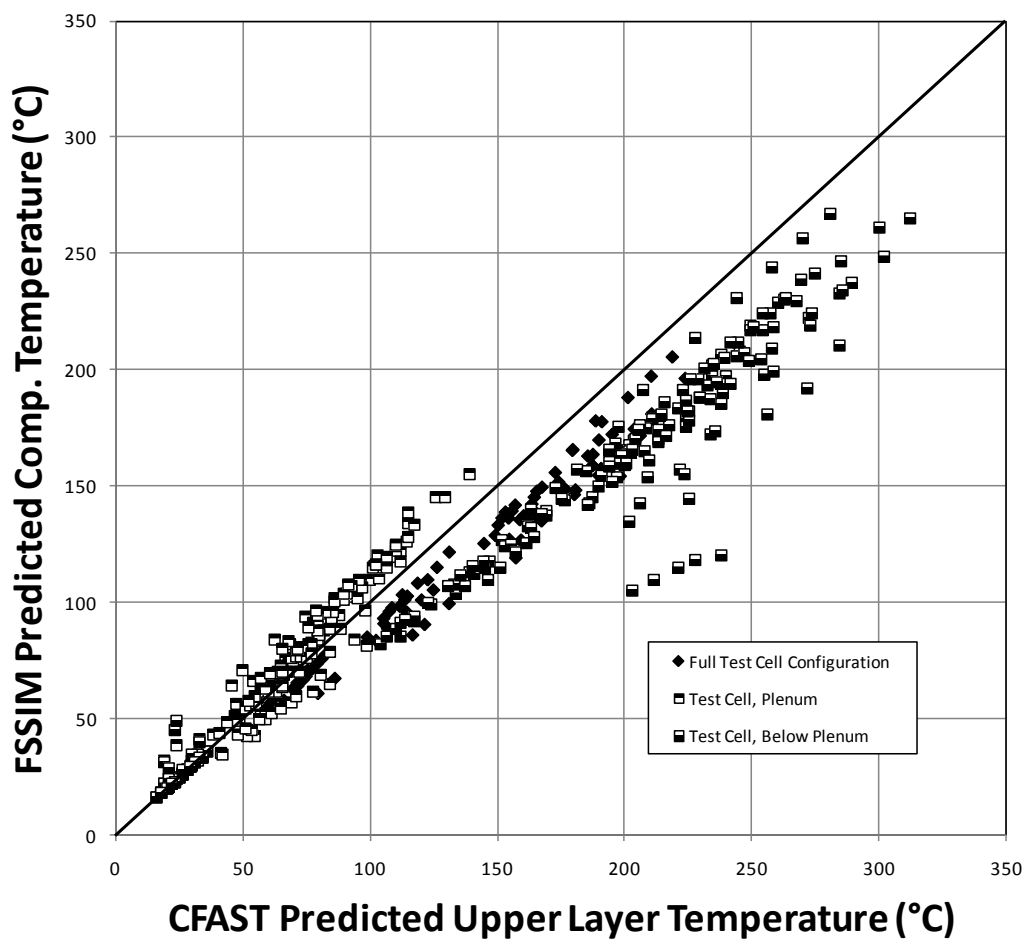

Fig. 8. Comparison of FSSIM predicted average compartment temperatures to CFAST predicted upper layer temperatures.

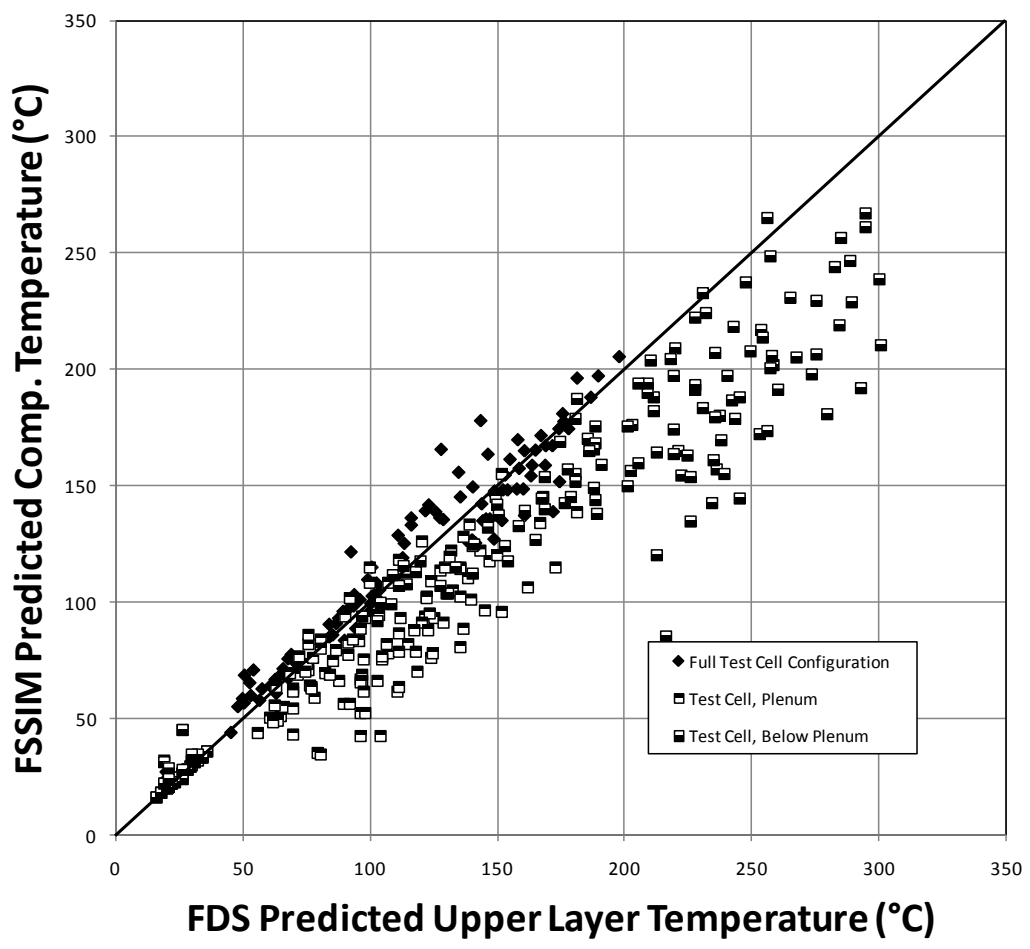

Fig. 9. Comparison of FSSIM predicted average compartment temperatures to FDS predicted upper layer temperatures. 


\section{CONCLUSIONS}

The results of the numerical simulations applied in this simplistic design approach produce favorable predictions for each of the three fire models examined. On the average, FSSIM, CFAST and FDS predict temperatures that are conservative (high) when compared to similar reported experimental data. The differences between the three models are mostly associated with resolution. FSSIM produces a single average temperature for the compartment, CFAST produces two average temperatures for the compartment and FDS can produce a detailed temperature field throughout the compartment.

This study also identifies substantial variability in results as indicated by minimum and maximum error estimates, and the estimated relative model uncertainty. However, this is not necessarily an indictment on the performance of the models, as some of the variability is attributable to the unknown experimental uncertainty. Substantial verification and validation has been performed in support of each of these models since their inceptions, many of which demonstrate lower average error than reported by this study [6]. This study is not intended to be used as an overall measure of model fidelity, but as a comparison of the models as they would typically be applied in a design scenario where many inputs must be substantially simplified.

This analysis suggests that the use of the network model approach can produce reasonable results for the global performance of a compartment fire with a dramatic reduction in computational cost. The range of applicability of FSSIM can be extended to include substantially elevated fuel sources by applying the novel methodology introduced in this study. In the context of a design fire hazard analysis where additional conservatism is desired, FSSIM predicted temperature differences above ambient can be reasonably corrected by a factor of $10 \%$ to $20 \%$. This does not necessarily apply to all fire hazard analyses, as there are other methods for establishing conservative results. Additionally, the advantages gained in the design process by using models with substantially lower computational costs can be substantial. The faster models, such as FSSIM and CFAST, can easily allow for sensitivity analyses to be performed in support of a design strategy as proposed by Hostikka et al. [10]. These models also allow simulation of multiple compartments connected by complex ventilation systems where application of FDS could be prohibitive. This modeling methodology would be used to identify scenarios in which more detailed analysis with tools such as FDS is desired.

\section{REFERENCES}

[1] Foote, K.L., "1986 LLNL Enclosure Fire Tests Data Report," UCID-21236, Livermore, CA: Lawrence Livermore National Laboratory, 1987.

[2] Floyd, J., Hunt, S., Williams, F., and Tatem, P., "Fire and Smoke Simulator (FSSIM) Version 1.5 - Theory Manual," NRL/MR/6180-04-8765, Washington, DC: Naval Research Laboratory, 2008.

[3] Floyd, J., Hunt, S., Williams, F., and Tatem, P. , (2005) A Network Fire Model for the Simulation of Fire Growth and Smoke Spread in Multiple Compartments with Complex Ventilation, Journal of Fire Protection Engineering 15(3): 199-229, http://dx.doi.org/10.1177/1042391505051358

[4] Jones, W., Peacock, R., Forney, G. and Reneke, P., "CFAST - Consolidated Model of Fire Growth and Smoke Transport (Version 6) Technical Reference Guide," NIST SP-1026, Gaithersburg, MD: National Institute of Standards and Technology, 2009.

[5] McGrattan, K., Hostikka, S., Floyd, J., Baum, H., Rehm, R., Mell, W., McDermott, R., "Fire Dynamics Simulator (Version 5) Technical Reference Guide, Volume 1: Mathematical Model," NIST SP-1018-5, Gaithersburg, MD: National Institute of Standards and Technology, 2009.

[6] McGrattan, K., Hostikka, S., Floyd, J., McDermott, R., "Fire Dynamics Simulator (Version 5) Technical Reference Guide, Volume 3: Validation," NIST SP-1018-5, Gaithersburg, MD: National Institute of Standards and Technology, 2010.

[7] Beyler, C., (1991) Analysis of Compartment Fires with Overhead Forced Ventilation, Fire Safety Science 3: 291-300, http://dx.doi.org/10.3801/IAFSS.FSS.3-291

[8] Peatross, M. and Beyler, C., (1997) Ventilation Effects on Compartment Fire Characterization, Fire Safety Science 5: 403-414, http://dx.doi.org/10.3801/IAFSS.FSS.5-403 
[9] Hill, K., et al., "Verification and Validation of Selected Fire Models for Nuclear Power Plant Applications," NUREG 1824, Washington, DC: United States Nuclear Regulatory Commission, 2007.

[10] Hostikka, S., Korhonen, T., and Keski-Rahkonen, O., (2005) Two-model Monte Carlo Simulation of Fire Scenarios, Fire Safety Science 8: 1241-1252, http://dx.doi.org/10.3801/IAFSS.FSS.8-1241 